\title{
El uso de modelos digitales de elevación y ortoimágenes para la determinación de los cauces de cuencas hidrológicas de la zona de Tixtla, Guerrero
}

\author{
Juan Javier Durón Díaz*
}

Recibido el 15 de julio de 2014; aceptado el 24 de febrero de 2015

\section{Resumen}

El Instituto Nacional de Estadística y Geografía (INEGI) como la agencia geográfica de México, tiene por objetivos el producir datos e información geoespacial con la finalidad de suministrar a la sociedad y al Estado información de calidad, pertinente, veraz y oportuna, a efecto de coadyuvar al desarrollo nacional. Esto ha derivado a que el INEGI genere grupos de datos geográficos cuya utilización permitan apoyar en la toma de decisiones de alcance nacional como la prevención y atención de desastres, seguridad nacional, ordenamiento territorial, desarrollo urbano, diseño y planeación de edificaciones, delimitación de zonas naturales protegidas, hidrografía e hidrología, medio ambiente, energía, comunicaciones y transportes, construcción de infraestructura y en diversos proyectos, objetivos, actividades y fines, cuyo propósito es que sean útiles para el diseño, la implementación y la evaluación de políticas públicas para el avance y desarrollo de la República Mexicana. Entre la diversidad de datos geográficos que produce el INEGI se encuentran los correspondientes al relieve continental e insular y las imágenes del territorio, estos datos digitales alcanzan su potencial máximo cuando son relacionados espacialmente en sistemas de información geográfica para ofrecer a los usuarios y especialistas un abanico de opciones en el modelado y análisis topográfico del territorio con una gran aproximación a lo real y con las variantes y ventajas que ofrece la tecnología informática hoy en día aplicada a la geografía digital. En este trabajo se dan a conocer los procesos para la determinación de los cauces de cuencas hidrológicas de la zona de Tixtla, Guerrero, mediante el uso de los datos digitales del relieve y ortoimágenes con la utilización de sistemas de información geográfica, ya que éstos tienen una importancia no solo en la combinación e integración de datos geoespaciales, sino en la capacidad que tienen para extraer información referente a los cauces o escurrimientos de agua necesarios para

* Instituto Nacional de Estadística y Geografía (INEGI), Avenida Héroe de Nacozari Sur 2301, Fraccionamiento Jardines del Parque, 20276, Aguascalientes, Ags., México, correo electrónico: javier.duron@inegi.org.mx 
realizar un modelado hidrológico, esto mediante operaciones espaciales usadas en algoritmos para tal fin mediante el uso de los modelos digitales de elevación de tipo terreno que permiten modelar la interacción entre la forma del terreno y sus procesos de transporte de agua y sedimentos. Esto permitirá obtener información geográfica para analizar el entorno de la cuenca hidrológica de Tixtla, y en su caso disponer de elementos ante la posibilidad de conocer los posibles riesgos que pueda tener ante la presencia de fenómenos hidrometeorológicos que causen inundaciones, logrando con ello promover una cultura de la seguridad y autoprotección para que se fortalezcan en la propia ciudadanía, logrando avanzar hacia mejores condiciones de vida, facilitando la capacidad de respuesta de las propias comunidades ante la presencia de cualquier fenómeno o agente perturbador que pudiera afectar la seguridad de la población de Tixtla, Guerrero.

Palabras clave: INEGI, Geografía, Modelos Digitales de Elevación, ortoimágenes, hidrología.

\section{Abstract}

The National Institute of Statistics and Geography (INEGI), as the Mexican geographical agency, aims to produce geospatial data and information in order to provide to the society and state quality information, persistent, accurate and opportune, in order to contribute to national development. INEGI generates geographic data groups that permit make decision at national level as prevention and disaster attention, national security, territorial regulation, urban development, planning and design of buildings, protected natural zones, hydrography and hydrology, environment, energy, communications and transport, infrastructure construction and different projects, objectives, activities and targets, the objective is to be useful for the design, implementation and evaluation of public policies directed to the progress and development of Mexico. Among the diversity of geographic data produced by INEGI are the corresponding to continental and insular relief and territory images, these digital data reach their full potential when they are spatially related to geographic information systems providing users and specialists a broad options in modelling and topographic analyze of the territory with a great approach to the reality and advantages and variants of computer technology applied to digital geography. This work makes known the processes for determining riverbeds basins for Tixtla in Guerrero State area, using terrain relief digital data and orthoimages also with the use of geographic information systems, as they have an importance not just in the combination and integration of geospatial data, but the capacity to extract information about riverbeds or water flow needed for hydrological modeling this by spatial operations used and algorithms, for this purpose using digital elevation models that allow modelling the interaction between landform and transport of water and sediments process. This will allow obtain geographic information to analyze the Tixtla's watershed environment, and if have elements facing 
the possibility to know the risks that may be in the presence of hydrometeorological phenomena causing floods, thus achieving promote a safety culture and self-protection by the strengthening of citizens themselves, achieving progress towards better living conditions, providing the responsiveness of the communities in the presence of any phenomenon or disturbing agent that could affect the population safety of Tixtla, Guerrero.

Key words: INEGI, Geography, Digital Elevation Models (DEMs), Orthoimages, Hydrology.

\section{Resumo}

O Instituto Nacional de Estatística e Geografia (INEGI) como agência geográfica México tem como objetivo produzir dados e informações geoespaciais, a fim de proporcionar à sociedade e à qualidade da informação do estado, relevante, precisa e oportuna, a fim de contribuir para o desenvolvimento nacional. Isto levou ao INEGI gera grupos cujos dados geográfico utilizado para sustentar a nível nacional na prevenção e alívio de desastres, a segurança nacional, o planejamento territorial, desenvolvimento urbano, design e planejamento de edifícios, a delimitação de áreas naturais de tomada de decisão protegidas, hidrografia e hidrologia, meio ambiente, energia, comunicações e transportes, de construção de infra-estruturas de múltiplos projetos, objetivos, atividades e propósitos, que se destina a ser útil para o desenho, implementação e avaliação de políticas públicas para o avanço e desenvolvimento do México. Entre a diversidade de dados geográficos produzidos pelo INEGI são relevantes para alívio e imagens do território continental e insular, estes dados digitais atinge o seu pleno potencial quando são espacialmente relacionados sistemas de informação geográfica para fornecer aos usuários e especialistas um fã Opções na modelagem e análise topográfica do território com uma grande aproximação ao real e as variantes e as vantagens da moderna tecnologia informática aplicadas a dia geografia digital. Este artigo descreve processos para determinar canais área da bacia Tixtla, Guerrero, usando dados digitais e alívio orto-imagens com o uso de sistemas de informações geográficas, como eles têm uma importância não só na combinação e integração de dados geoespaciais, mas a capacidade de extrair informações sobre os canais ou escoamento de água necessária para a modelagem hidrológica, este espaço de operações utilizado em algoritmos para este fim, usando modelos de elevação digital do terreno que permitem que tipo de modelo a interação entre os processos de paisagem e de transporte de água e sedimentos. Isto irá fornecer informação geográfica para analisar o ambiente da bacia hidrográfica do Tixtla, e se têm elementos que revelam os riscos potenciais na presença de fenômenos hidrometeorológicos causando inundações, conseguindo, assim, promover uma cultura de segurança e autoproteção para o reforço dos próprios cidadãos, a realização de progressos no sentido de melhores condições de vida, facilitando a capacidade de resposta das próprias comunidades, na 
presença de qualquer fenômeno ou agente perturbador que possa afetar a segurança da população de Tixtla, Guerrero.

Palavras-chave: INEGI, Geografia, dems, orto-imagens, hidrologia.

\section{Modelos digitales de elevación}

Los modelos digitales de elevación forman parte del grupo de datos del relieve continental, insular y submarino del Subsistema Nacional de Información Geográfica y del Medio Ambiente de México y son una estructura numérica de datos que contiene los valores de elevación de las formas del relieve terrestre como son las montañas, planicies, cañones, talud y plataforma continental, fosas, depresiones, dorsales y mesetas, así como de los objetos naturales y artificiales presentes sobre el relieve, que permiten modelar estos espacios geográficos para conocer aspectos tales como alturas, profundidades, pendientes, secciones, desniveles, volúmenes y delimitación de cuencas, con el fin de coadyuvar al desarrollo de México y a la generación del conocimiento y estudio de las formas del relieve como un factor determinante en las condiciones físico ambientales, recursos naturales, diseño de infraestructura y, en su caso, atender emergencias o catástrofes originadas por desastres naturales (Figura 1).

Hoy en día existe la posibilidad de generar diferentes tipos de modelos en los que se encuentran los de superficie y los del terreno, siendo los primeros la estructura numérica de los valores de altura de las formas del relieve terrestre con respecto a un nivel de referencia o nivel medio del mar en la cual también se incluyen los valores de los objetos presentes sobre el relieve, como pueden ser los referentes a la vegetación, naufragios, obstrucciones, edificaciones e infraestructura. Los modelos digitales del terreno son la estructura numérica de los valores de altura de las formas del relieve terrestre con respecto a un nivel de referencia o nivel medio del mar sin considerar los objetos presentes sobre el relieve, es decir, habiendo removido los valores de los elementos naturales y los hechos por el hombre (Figura 2).

Existen varios métodos para generar modelos digitales de elevación, así como diversa información geográfica de altimetría que se puede emplear para producir los modelos tales como los datos de RADAR, procesos fotogramétricos, LIDAR, observaciones en campo para obtener datos geodésicos y topográficos, curvas de nivel y actualmente también se pueden generar con la utilización de datos provenientes del procesamiento de imágenes captadas de sensores satelitales en modo estereoscópico, siendo este último el empleado por el INEGI para la mayor parte del país, ya que ofrece la oportunidad de disponer de información para "ver" mediante la imagen óptica, que al ser captada en modo estereoscópico también permitirá obtener datos de altimetría para "medir" del mismo espacio geográfico y misma temporalidad de la zona a modelar (Figura 3). 


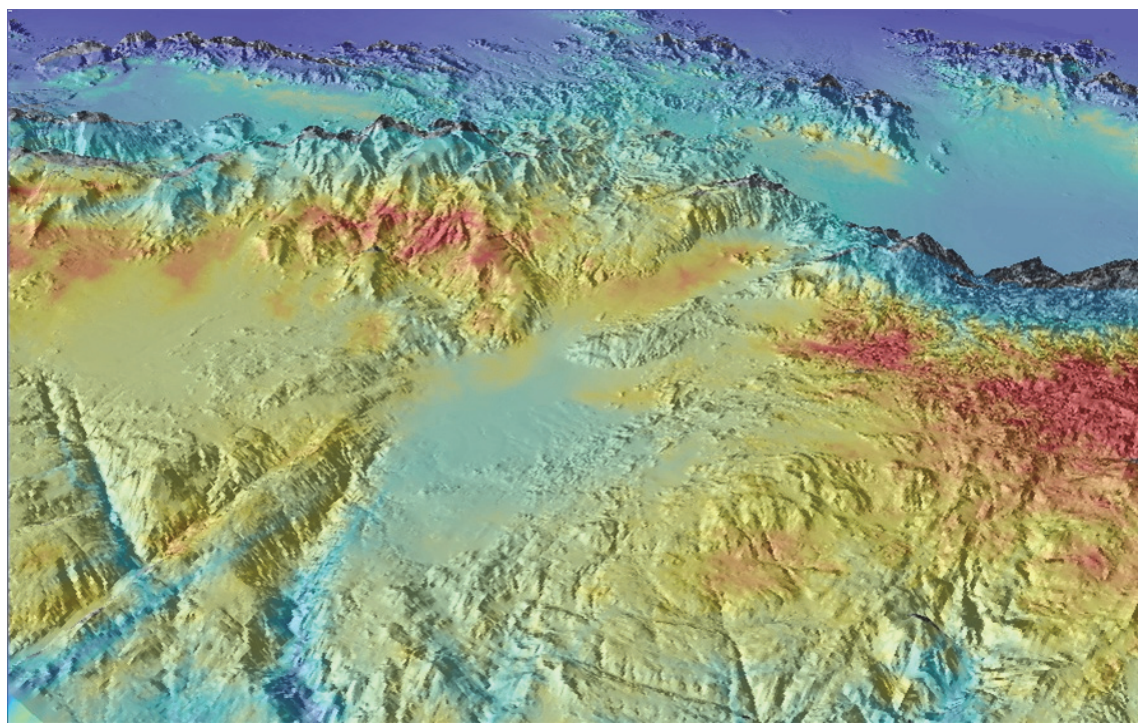

Figura 1. Modelo digital de elevación con representación de hipsometría en base a los rangos de elevación que contiene el modelo.

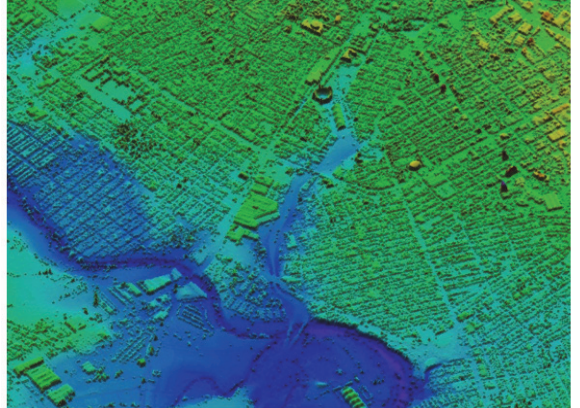

Modelo digital de superficie en el cual también se incluyen los valores de los objetos presentes sobre el relieve.

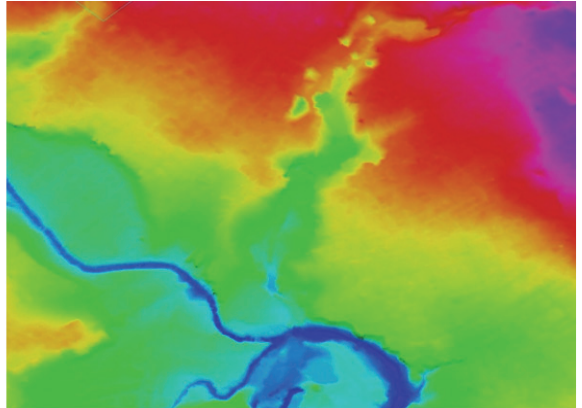

Modelo digital de terreno sin considerar los objetos presentes sobre el relieve.

Figura 2. Diferencia entre los modelos digitales de elevación de tipo superficie y del terreno con resolución de $5 \mathrm{~m}$ de la zona de Aguascalientes. 


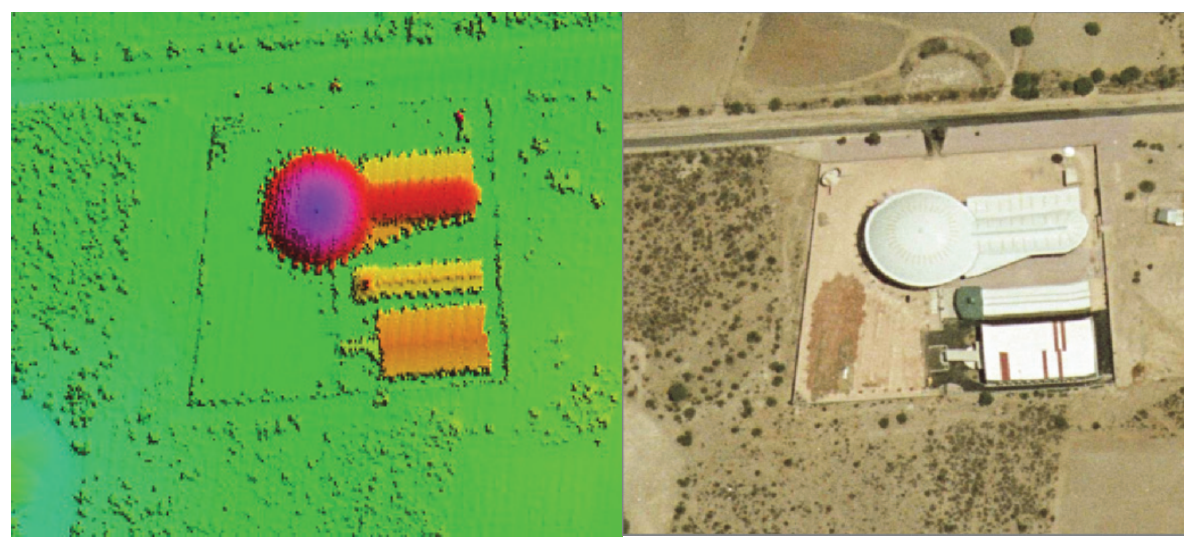

Datos de altimetría en donde cada dato tiene posición geográfica y elevación.

Imagen óptica que permite ver el entorno de la zona.

Figura 3. Modelo digital de elevación e imagen óptica captada en modo estereoscópico con la cual es posible obtener datos de altimetría para generar modelos digitales de elevación.

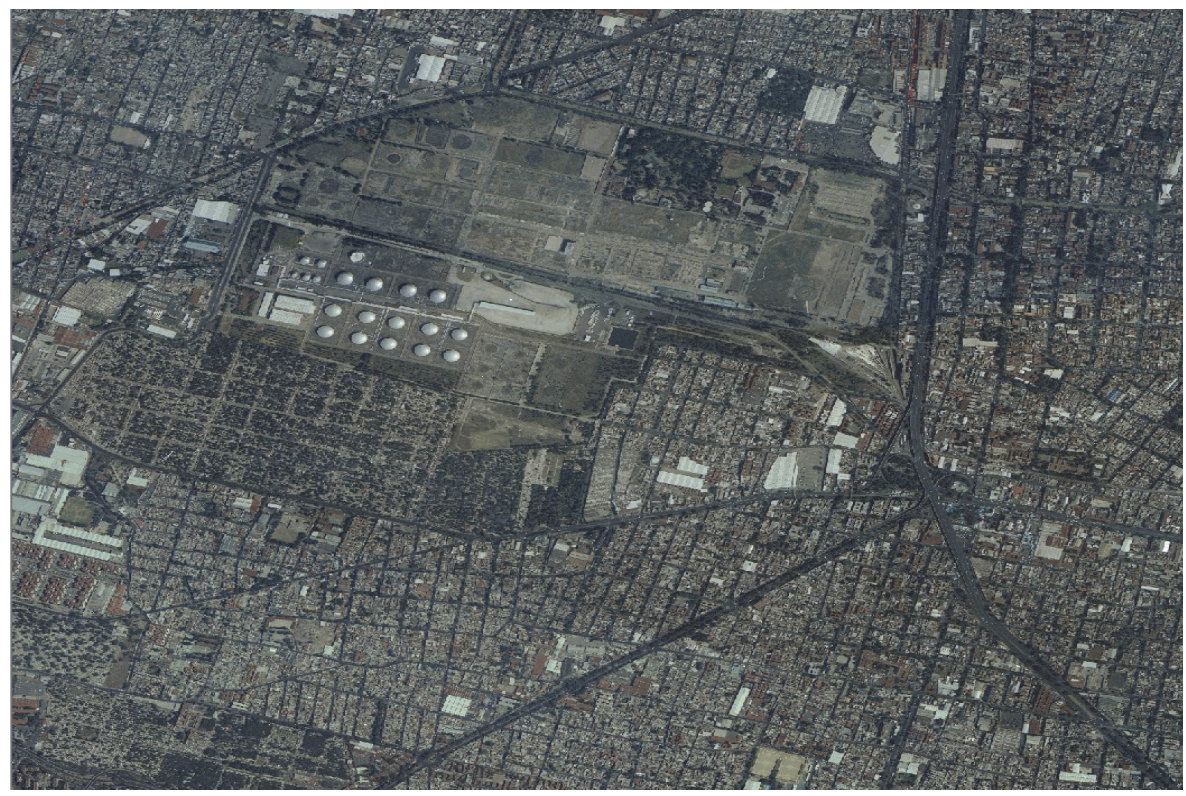

Figura 4. Ortoimagen digital de $50 \mathrm{~cm}$ de resolución correspondiente a la zona urbana del Distrito Federal, México. 


\section{Ortoimágenes}

Estos datos geográficos relacionados con las imágenes del territorio se obtienen del proceso fotogramétrico que se aplica a imágenes ópticas captadas en modo estereoscópico y que asegura que cada elemento de la imagen o pixel, esté en su posición geográfica correcta, corresponde en esencia a transformar el sistema de proyección central de la imagen a una proyección ortogonal, en la cual han sido removidos los desplazamientos causados por la inclinación de la cámara o sensor y el relieve del terreno. Está referida a una proyección cartográfica, por lo que posee las características geométricas de un mapa, además de la calidad pictórica de la fotografía (Figura 4).

Para obtener las ortoimágenes, el INEGI realiza procesos previos para tal fin en los que se elabora un control de calidad a las imágenes ópticas que son captadas verificando que la cobertura de dichas imágenes no sobrepasen el porcentaje de nubes en la toma, así como verificar que la cobertura territorial de las mismas cubran la zona definida en la planeación previa del proyecto. Posteriormente con el apoyo de información proveniente de observaciones en campo con equipo de medición y la aplicación de métodos geodésicos y topográficos se obtienen puntos de posición conocida en el terreno denominados en conjunto "control terrestre", el cual es necesario para que se efectué el siguiente proceso, la aerotriangulación, la cual es el proceso que tiene por objeto obtener las coordenadas de diversos puntos del terreno mediante los procedimientos de la fotogrametría, para obtener la posición del mayor número posible de estos puntos de apoyo mediante operaciones fotogramétricas.

El proceso de aerotriangulación relaciona física y matemáticamente las imágenes individuales y las asocia a todo el proyecto con la referencia horizontal y vertical. El proceso de aerotriangulación digital elimina el trabajo tradicional que conlleva a los clásicos errores, lográndose un ahorro sustancial para el proyecto a través de procesos automatizados, posteriormente se genera la ortoimagen en la cual se puede transformar una imagen en una proyección del terreno, la rectificación corrige los desplazamientos existentes en la imagen original producidos por la inclinación del eje de la toma. La imagen rectificada debe tener las características geométricas de una proyección ortogonal del objeto captado en la imagen sobre un cierto plano y a una determinada escala.

Las propiedades de las ortoimágenes permiten que estos datos geográficos ofrezcan al menos la misma precisión que los mapas, en donde cada píxel tiene una posición claramente determinada en el sistema de referencia. Están calibradas respecto a los colores y por medio de los módulos de ajuste radiométricos y de formación de mosaicos se pueden fusionar dos o más ortoimágenes y producir una imagen de color homogénea de mejor calidad y multitemporalidad. Las ortoimágenes pueden adoptar escalas variables; al ser imágenes de tipo raster se pueden aplicar técnicas de clasifi- 
cación a las imágenes ya sean en color o en infrarrojo color. La propiedad multitemporal, multiescalar y multiespectral son exclusivas de las ortoimágenes, pueden compararse con datos provenientes de teledetección con objeto de completar el proceso de interpretación con otros canales multiespectrales. Se pueden utilizar para hacer cálculos de superficies, distancias, desplazamientos, entre otros, y que debido a su carácter multidisciplinario, constituyen una fuente de datos muy útil para usuarios de sistemas de información geográfica (Figura 5).

En el INEGI, el proceso para la generación de ortoimágenes y modelos digitales de elevación mediante el uso de imágenes digitales estereoscópicas tiene diversidad de actividades que permiten la producción de estos datos geoespaciales del relieve y de imágenes del territorio, para la cual se establecen instrumentos de seguimiento y control para la mejor ejecución de cada uno de los procesos para derivar los productos geográficos que forman parte del Sistema Nacional de Información Estadística y Geográfica de México.

\section{Ubicación del proyecto}

Tixtla se localiza en la porción central del estado de Guerrero, en las coordenadas $17^{\circ}$ $20^{\prime}$ y $17^{\circ} 43^{\prime}$ de latitud Norte y en los meridianos $99^{\circ} 15^{\prime}$ y $99^{\circ} 28^{\prime}$ de longitud Oeste respecto al meridiano de Greenwich y forma parte de la región Centro. Sus límites territoriales son al norte con el municipio de Mártir de Cuilapan, al sur con los municipios de Mochitlán y Chilpancingo de los Bravo, al oriente con Zitlala y Chilapa de Álvarez y al poniente con Eduardo Neri y Chilpancingo de los Bravo (Figura 6).

\section{Descripción del trabajo}

Para generar la ortoimagen y obtener datos de altimetría para el modelo digital de elevación de la zona de Tixtla, se captaron imágenes ópticas en modo estereoscópico, las cuales fueron verificadas mediante un control de calidad para corroborar que no tuvieran más del $10 \%$ de nubosidad, posteriormente usando puntos de control geodésico, observados con equipo GPS y mediante procesos fotogramétricos, las imágenes se procesaron para obtener su orientación, obteniendo valores de parámetros de orientación de las mismas en coordenadas XYZ y ángulos de rotación Kappa, Phi y Omega, ello permite obtener bloques de imágenes orientadas, posibilitando alcanzar buenas precisiones para la generación de ortoimágenes y datos de altimetría (Figura 7).

Obtenido el bloque orientado se procedió a realizar el proceso de ortorrectificación de las imágenes con el fin de reducir las distorsiones en la imagen producidas por la propia geometría de formación de la imagen en el sensor y la curvatura de la superficie de la Tierra, para la ortorrectificación se aplicaron procesos fotogramétricos, para representar la proyección ortogonal sin efectos de perspectiva para ello fue 

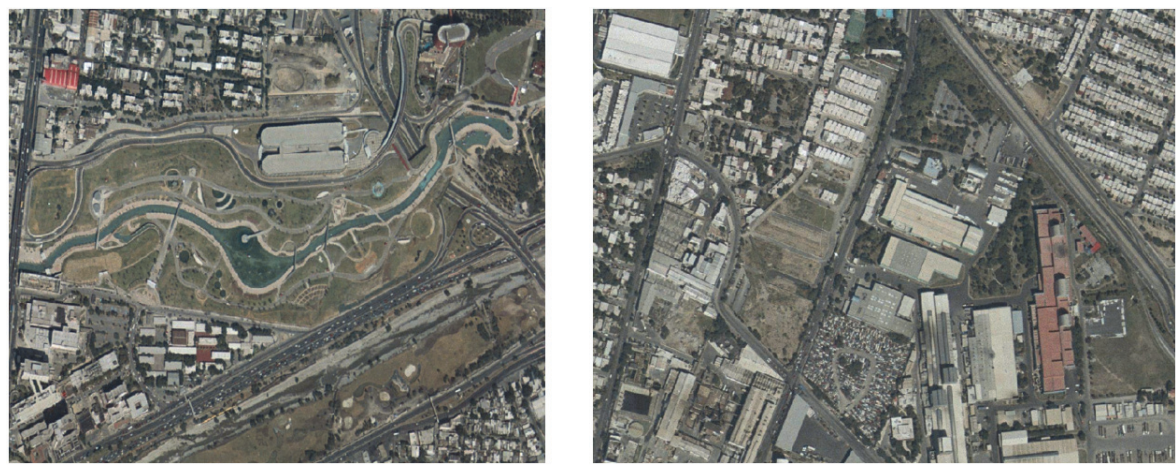

Figura 5. Ortoimágenes a color correspondientes a la zona urbana de Monterrey, Nuevo León, México, con las cuales se pueden realizar medición de superficies, distancias, desplazamientos, entre otros.

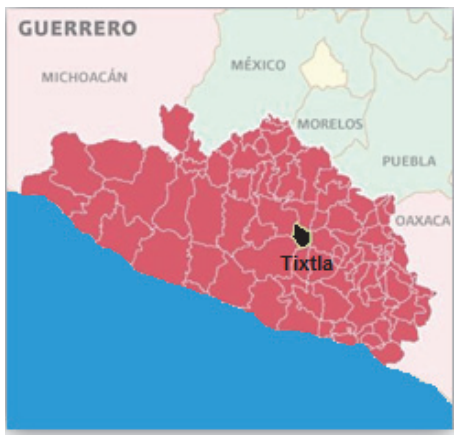

Ubicación de Tixtla, Guerrero

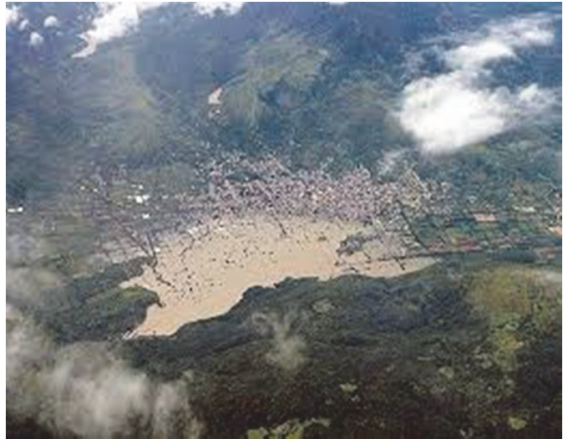

Imagen de la zona de Tixtla

Figura 6. Ubicación geográfica de Tixtla con respecto al estado de Guerrero e imagen de la zona.

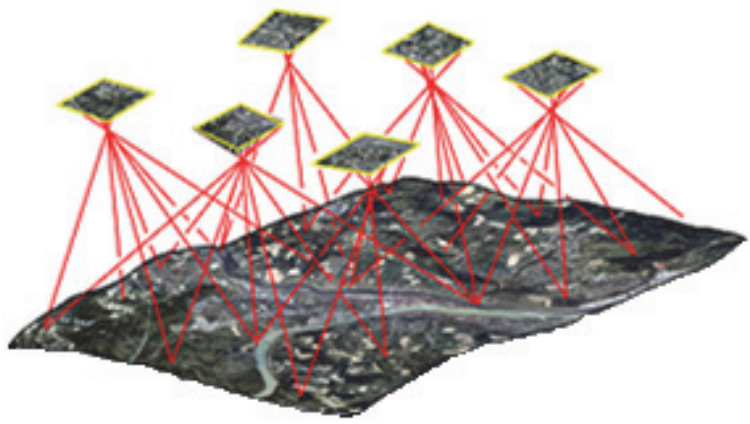

Figura 7. Representación gráfica del proceso de aerotriangulación en imágenes ópticas. 


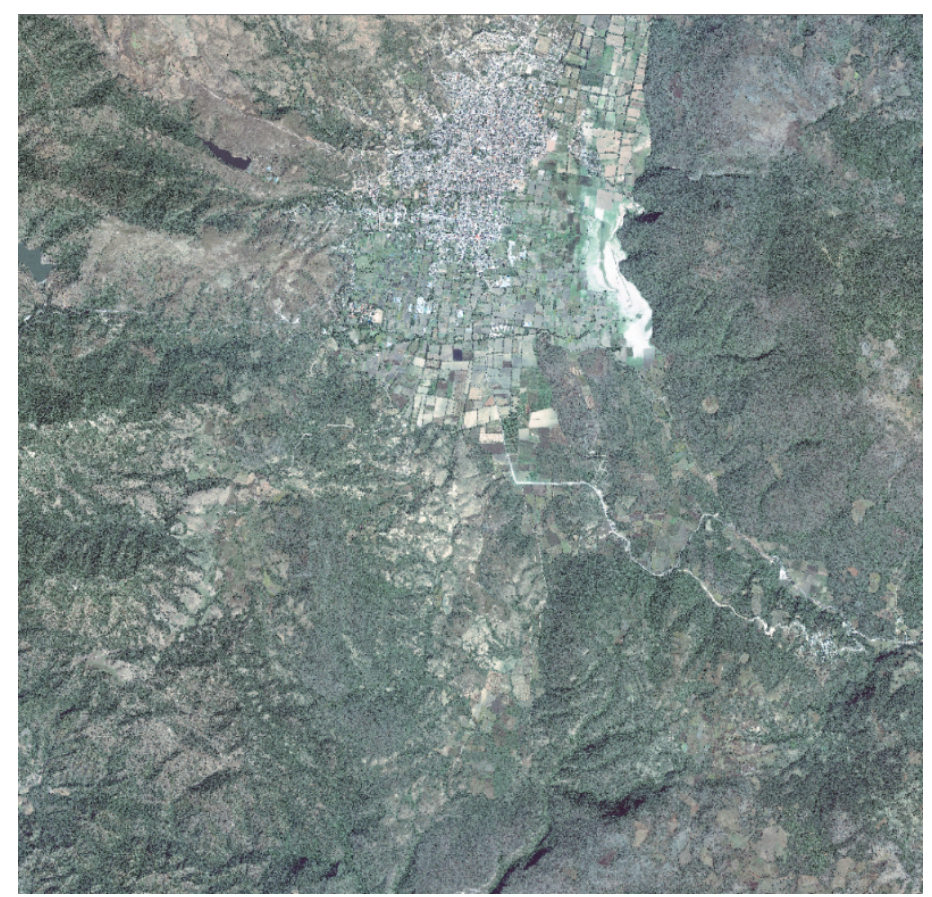

Figura 8. Ortoimagen digital generada por procesos fotogramétricos de Tixtla, Guerrero.

necesario un modelo digital de elevación, el cual se obtuvo directamente de las vistas tridimensionales de las imágenes orientadas (modelo estereoscópico), derivando como producto final de este proceso la ortoimagen digital (Figura 8).

El modelo digital de elevación de tipo terreno, fue generado mediante la aplicación de procesos de clasificación y filtrado a puntos de altimetría derivados del proceso de correlación fotogramétrica, realizada en la etapa de generación de la ortorrectificación de las imágenes o ortoimágenes digitales, esta clasificación se realizó en primer instancia para generar el modelo digital de superficie de la zona ejecutando un macro o programa informático automático de clasificación, para eliminar puntos altos y bajos con anomalías en su valor de altura, producto de una inadecuada correlación en las imágenes, posteriormente se realizó una clasificación interactiva en donde el especialista eliminó puntos con inconsistencias en su valor de altura que el proceso automático de clasificación no fue posible identificar.

Una vez que se obtuvo el modelo de superficie final se realizó la ejecución del macro informático automático para la clasificación de terreno, proceso en el cual identifica todos aquellos puntos que corresponden a infraestructura, vegetación, edificaciones, entre otros, para dejar únicamente los puntos que corresponden al terreno, y para el cual fue complementado por un proceso interactivo para clasificar aquellos 
puntos que el proceso automático no efectuó de manera eficiente (Figura 9). En esta etapa también se realizó la incorporación de información de líneas de quiebre y de cuerpos de agua restituidos con su valor de elevación para intervenir en el proceso de generación del modelo digital del terreno con un rango de elevaciones de 1,116 a 2,006m; esto permitió disponer de un modelo más apegado con la realidad para poder detectar los cauces o escurrimientos en el relieve (Figura 10).

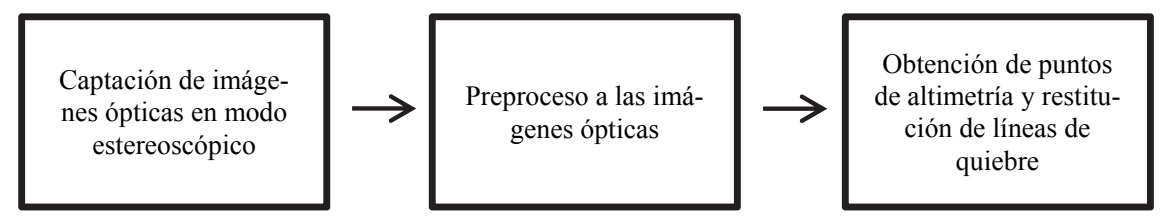

Figura 9. Proceso general para generar modelos digitales de elevación con el uso de imágenes captadas en modo estereoscópico.

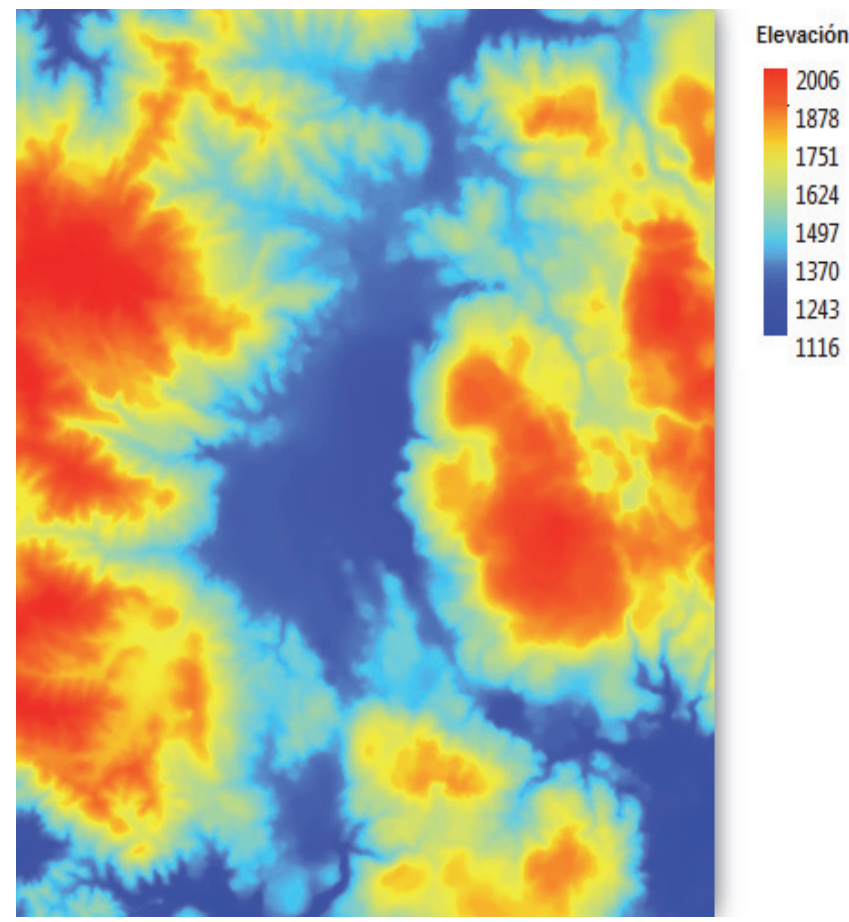

Figura 10. Modelo digital de elevación de tipo terreno generado por clasificación de puntos de altimetría de la zona de Tixtla, Guerrero. 
Habiendo generado la ortoimagen y el modelo digital del terreno, el primer ejercicio que se realizó como parte de la identificación de cauces o escurrimientos hidrológicos en la zona de Tixtla, fue mediante el uso de un Sistema de Información Geográfica (SIG) colocando la ortoimagen de fondo en la cual se identificaron y digitalizaron cada uno de los escurrimientos, teniendo una primera red de escorrentía para la zona que cubrieron las ortoimágenes elaboradas y para lo cual este mismo proceso se realizaría para toda la cuenca hidrológica de la zona (Figura 11).
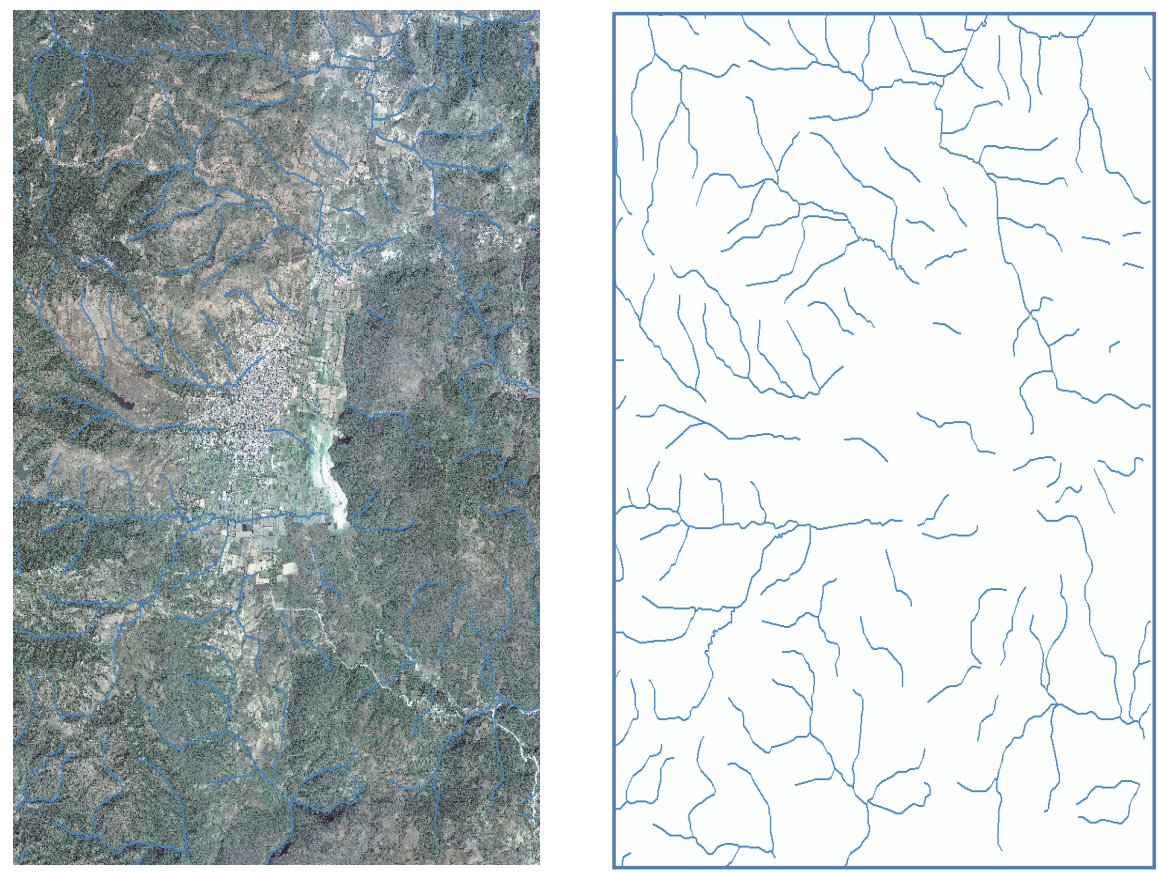

Figura 11. En la imagen de la izquierda la ortoimagen con los cauces de ríos y arroyos digitalizados sobrepuestos ambos en el SIG. En la imagen de la derecha el resultado obtenido de los cauces cercanos al asentamiento humano de Tixtla.

Realizando un segundo ejercicio, utilizando el modelo digital del terreno derivado de la clasificación y aplicando el procedimiento diseñado en el INEGI para generar cauces hidrológicos de manera semiautomática, fue posible derivar una segunda red, esto debido a la facilidad que tiene el procedimiento de auxiliarse de los valores de elevación del modelo digital para modelar la interacción entre la forma del terreno y sus procesos de flujo de agua, con ello delinear y caracterizar los afluentes que formen la cuenca hidrológica.

La base de este procedimiento de generación de cauces a partir del modelo, radica en definir las direcciones del flujo que tendrían los cauces de agua a partir del valor 
de cada pixel en el modelo digital del terreno, en donde la dirección de flujo está determinada por la dirección del descenso más empinado, o la caída máxima, desde cada pixel del modelo. Posteriormente, se calcula el flujo almacenado, como el peso acumulado de todos los pixeles que fluyen en cada pixel de pendiente descendente en un archivo ráster de salida, el cual dará origen al escurrimiento o cauce de agua en el relieve, ya que las celdas con una acumulación de flujo alta serán áreas de flujo concentrado y pueden ser útiles para identificar los arroyos y ríos.

Tomando en cuenta lo anterior, se realizó el procesamiento del modelo digital de elevación de tipo terreno para obtener los cauces referentes a ríos y arroyos en la zona de Tixtla, obteniendo como resultado una red conformada por 999 segmentos considerando un parámetro de acumulación de flujo de 800 celdas, esto quiere decir que tomará todos los pixeles que tienen más de 800 celdas que fluyen hacia ellas (Figura 12).

Posteriormente se realizaron otros procesamientos considerando diferentes parámetros de acumulación de flujo para 400, 200, 100 celdas, cuyos resultados se muestran en las Figuras 13 y 14:
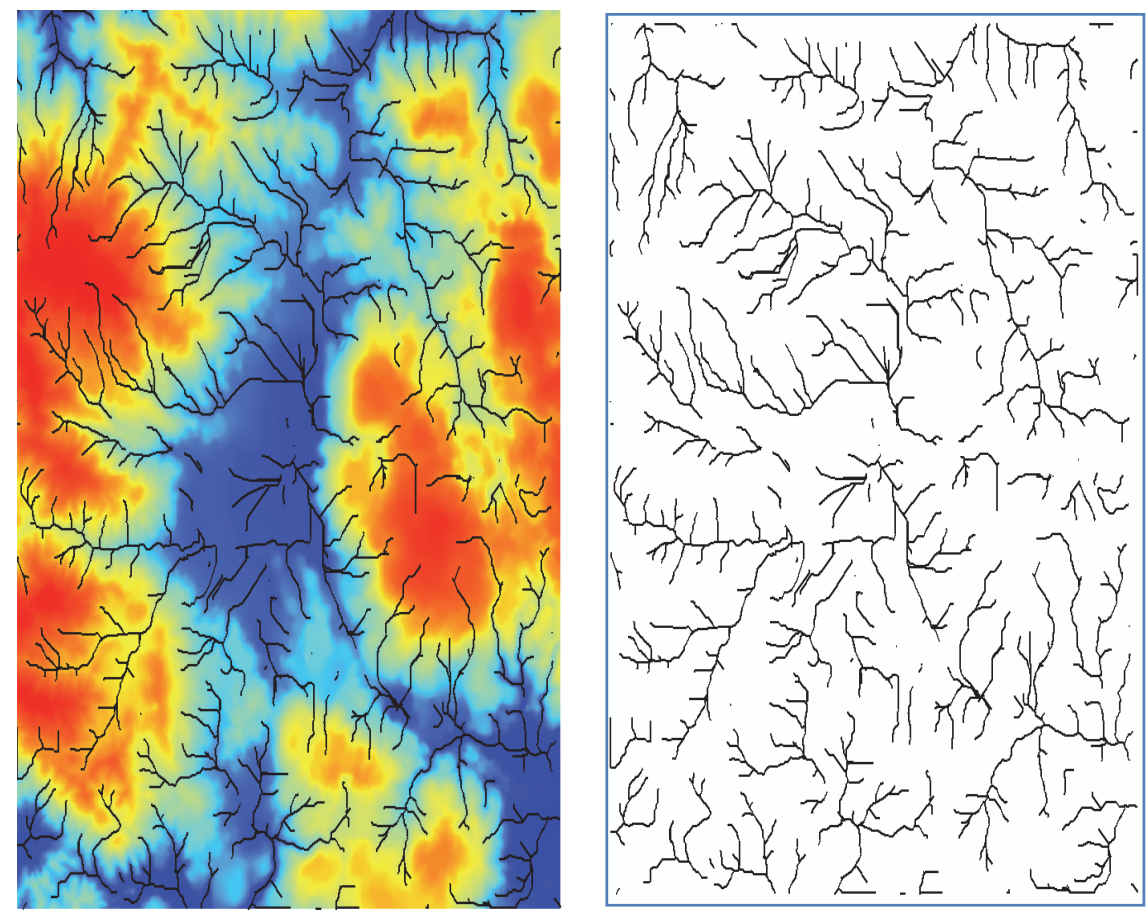

Figura 12. Modelo digital de terreno y los cauces derivados con un parámetro de acumulación de flujo de 800 pixeles y su resultado. 


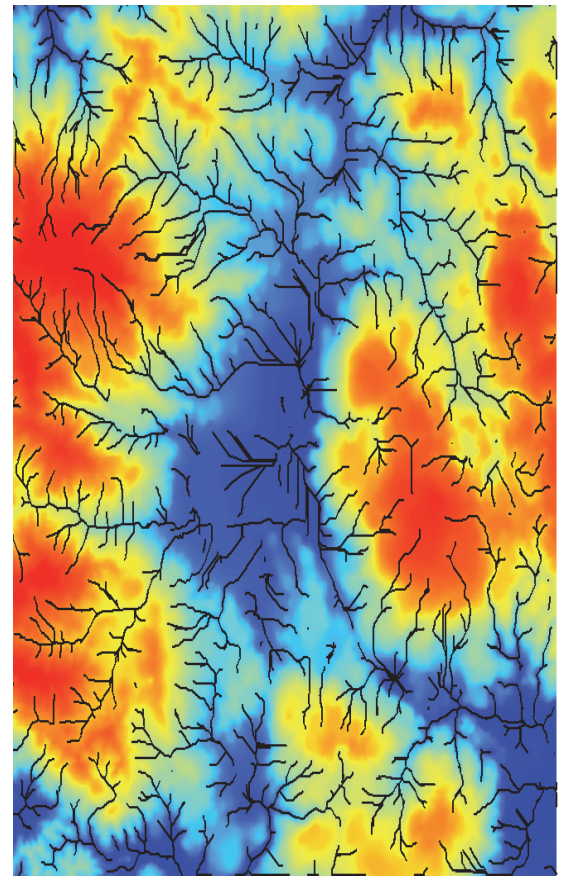

Modelo digital de terreno y los cauces derivados con un parámetro de acumulación de flujo de 400 pixeles, dando como resultado una red conformada por 1,919 segmentos.

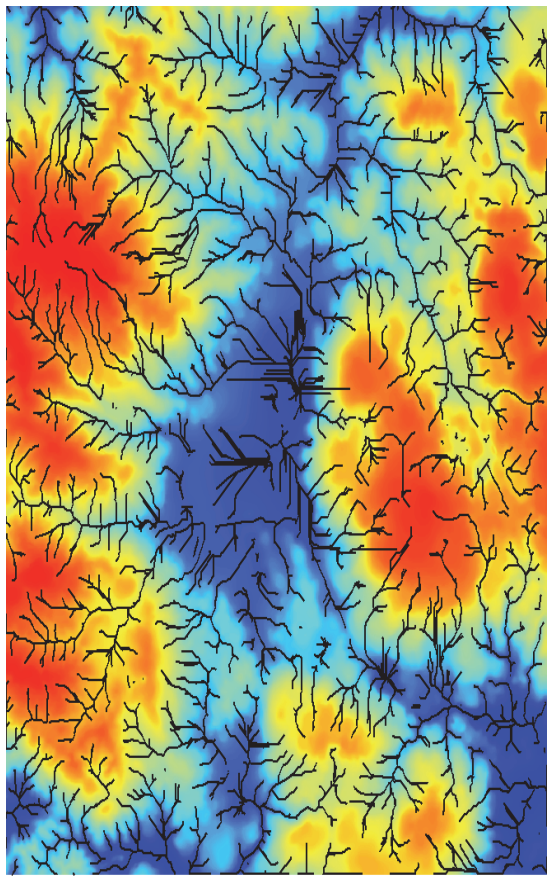

Modelo digital de terreno y los cauces derivados con un parámetro de acumulación de flujo de 200 pixeles, dando como resultado una red conformada por 3,937 segmentos.

Figura 13. Resultados obtenidos del procesamiento del modelo digital de terreno y los cauces derivados cambiando el valor del parámetro de acumulación de flujo.

\section{Conclusión}

Es posible obtener buenos resultados con el uso de los modelos digitales de elevación y las ortoimágenes para definir los cauces de una cuenca hidrológica, con la factibilidad de tener variantes en el número de segmentos que nos permitan ver los alcances que puedan tener en cuanto al número de escurrimientos que puedan formar parte de la red, y que a su vez permita su aplicación para diferentes propósitos a los usuarios para disponer de información de apoyo para diversos fines; por ejemplo, tomando en cuenta la red hidrológica y el modelo digital de elevación es posible realizar un modelado 3D de la zona de Tixtla con el fin de identificar cauces principales en base a los ramales o tributarios que van formando el cauce principal.

Otro análisis que podemos realizar en un SIG es sobreponiendo la ortoimagen, el modelo digital de elevación y la red hidrográfica derivada del propio modelo para 
realizar una comparación entre los causes mediante un modelado dinámico que nos permita reconocer puntos críticos en la zona derivado a la ubicación y cantidad de ramales máximos y longitudes de los mismos (Figuras 15 y 16).
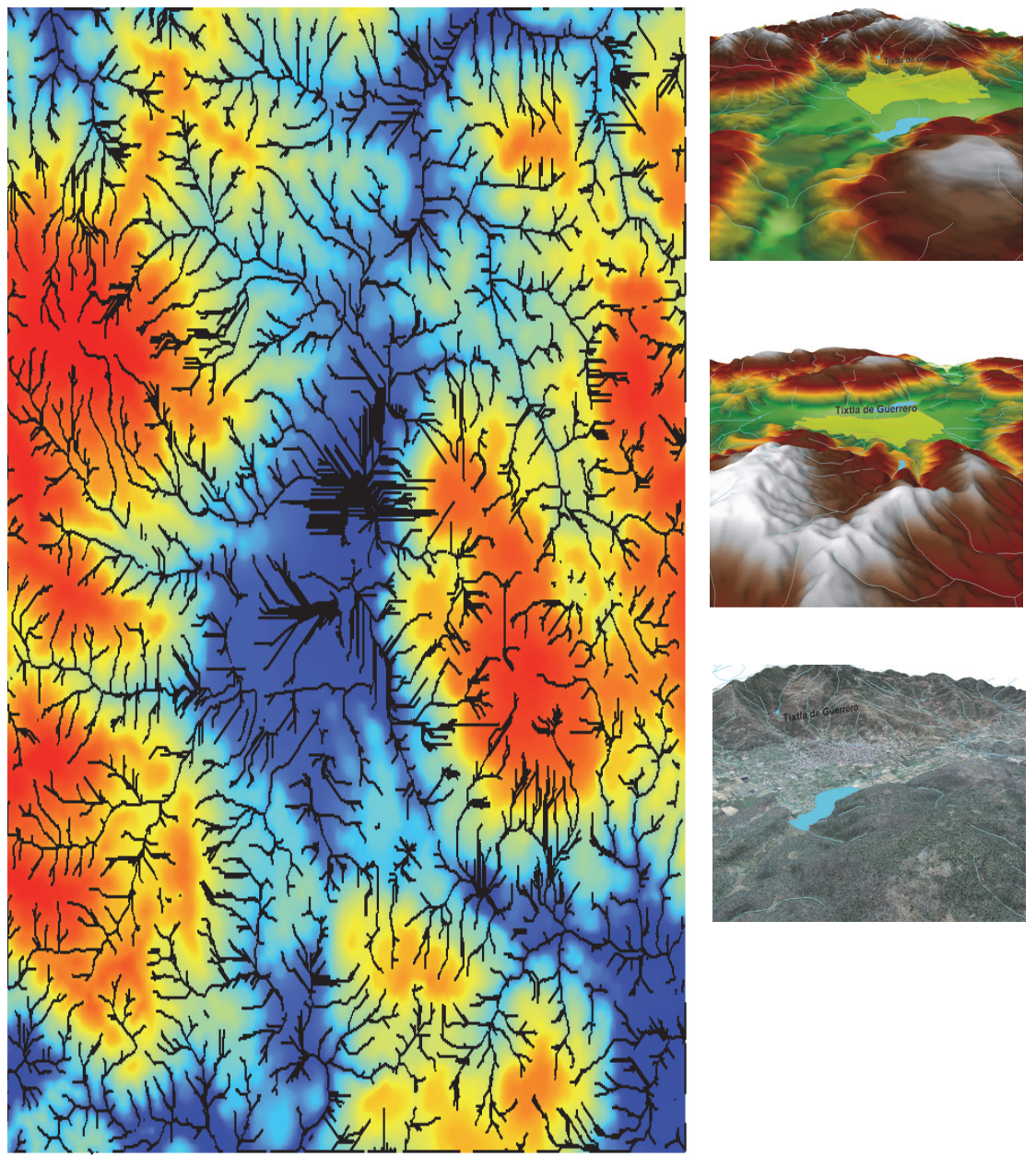

Figura 14. Modelo digital de terreno y los cauces derivados con un parámetro de acumulación de flujo de 100 pixeles y su resultado de 8,544 segmentos que conforma la red. A la derecha el modelo digital de elevación y ortoimagen en 3D con la ubicación geográfica de la localidad de Tixtla. 


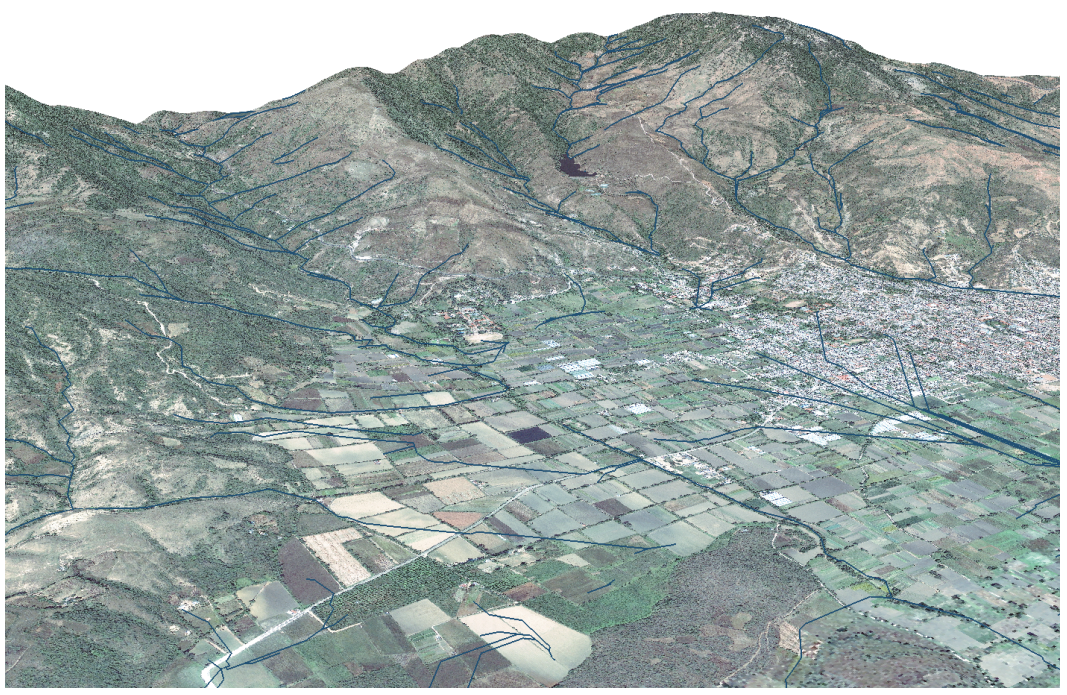

Figura 15. Modelado 3D en un SIG en donde se muestra la ortoimagen y la red de cauces generada a partir del modelo digital de elevación de tipo terreno con un parámetro de acumulación de flujo de 100 pixeles y su resultado de 8,544 segmentos en la zona de Tixtla.

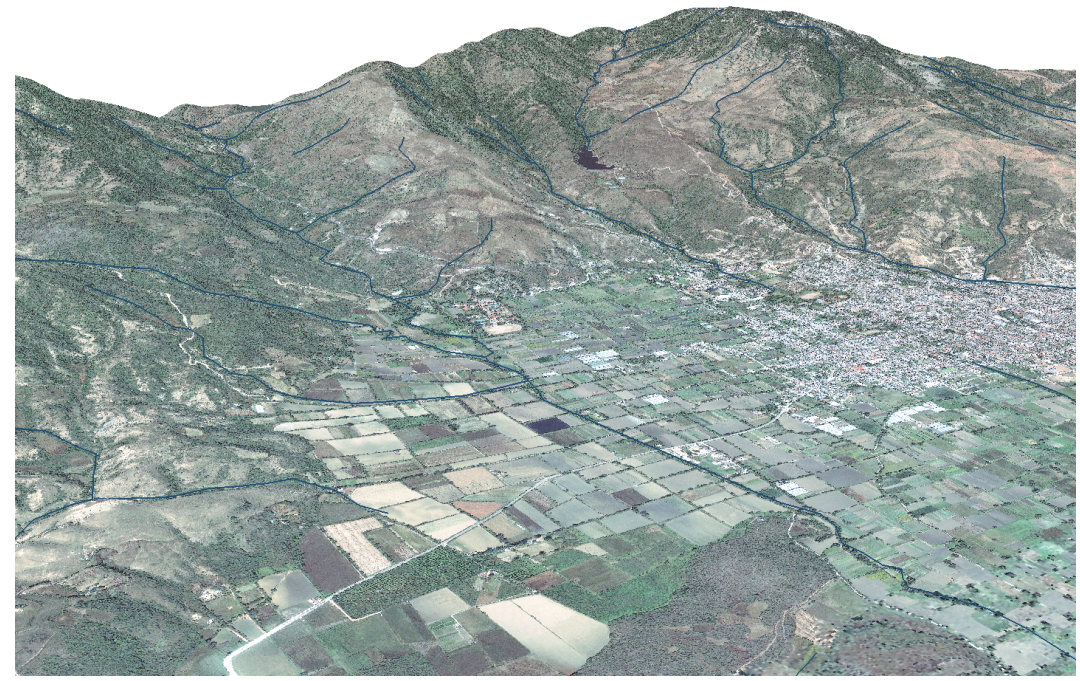

Figura 16. Modelado 3D en un SIG en donde se muestra la ortoimagen y la red de cauces generada a partir de la digitalización de cauces de la propia ortoimagen digital de la zona de Tixtla. 


\section{Bibliografía}

Durón Díaz, J.J., "Imágenes de satélite y datos LIDAR para zonas de costa y definición de elementos de infraestructura e hidrográficos", Memorias del XX Congreso Nacional de Ciencia y Tecnología del Mar, Aguascalientes, México, 2013, 10 pp.

Ramírez Osorio, J.M., Extracción automática de redes de drenaje a partir de modelos digitales del terreno, Universidad Nacional de Colombia, Medellín Colombia, 2002, 114 pp. 